\title{
A dimensão do cuidar no trabalho hospitalar: aborda- gem psicodinâmica do trabalho de enfermagem e dos serviços de manutenção*
}

The care dimension in hospital work: psychodynamic approach of nursing and maintenance services

\author{
${ }^{1}$ Maître de conferences. Laboratoire \\ de Psychodinamique du Travail. CNAM \\ - Paris. \\ Contato: \\ pmolinier@cnam.fr
}

\section{Resumo}

A partir da clínica e da teoria em psicodinâmica do trabalho, este artigo mostra a importância da dimensão da compaixão nas diversas atividades de cuidados hospitalares. Os resultados de investigações realizadas junto à enfermagem e às chefias de serviços técnicos revelam a dimensão de care contida em toda forma de trabalho no hospital. No entanto, cuidar não repousa apenas na boa vontade ou na grandeza da alma, mas pressupõe condições organizacionais concretas.

Palavras-chave: psicodinâmica do trabalho, enfermeiras, cuidados à saúde, supervisão de serviços técnicos hospitalares.

\begin{abstract}
Starting from both clinic and theory on work psychodynamics, this article shows the importance of the compassion dimension in several activities involving hospital care. The results of investigations held within nursing staff and technical service managers revealed a care dimension included in all kinds of hospital tasks. However, care taking depends not only on good will or greatness of the soul, but it implies concrete organizational conditions.
\end{abstract}

Keywords: psychodynamics of work, nurses, heath care, maintenance and technical hospital supervision. 


\section{Introdução}

O trabalho é invisível. A solidez e a estética de uma obra, o rigor de uma demonstração, o sabor de uma refeição podem ser julgados e apreciados. Mas as esperanças e as expectativas que o trabalho suscita, os esforços individuais e coletivos, as formas de inteligência que ele mobiliza, os sofrimentos e os prazeres, as remodelagens psíquicas onde ele é o palco, não se vêem. Certas atividades são ainda mais invisíveis. São aquelas que não se concretizam em um objeto ou numa realização técnica, ou não se objetivam diretamente. Pode-se quantificar o número de processos analisados por um serviço social ou de atos realizados em um serviço de atenção à saúde. Pode-se tentar avaliar as performances, mensurandoas por meio de índices (por exemplo, entre o número de patologias tratadas e o número de leitos ou a lista de espera de usuários). Mas a relação com pessoas doentes ou em situação de miséria não se avalia pelos critérios e métodos de gestão. Nenhuma pessoa de bom-senso contestará essa observação que, contudo, não impede a expansão das formas de avaliação gerencial nestes serviços. Assim, o trabalho hospitalar organiza-se hoje segundo os métodos emprestados das empresas do setor privado (polivalência, concorrência, terceirização, entre outros).

Não capturada pela avaliação gerencial, a dimensão relacional dos cuidados parece igualmente resistir a uma análise em termos de saber-fazer ou de habilidades. O "relacional" se define muito mais facilmente na esfera do não-trabalho que, propriamente, na do trabalho. Digamos, para tornar visível, que o sofrimento, a angústia e a agonia estão à espera de uma mão estendida, de um sorriso. Precisamente, a autenticidade de um gesto de consolo ou de súplica se manifesta como o contrário de um esforço laborioso, como uma atenção não calculada, um dom de si. Ou melhor, fala-se de saber-ser, uma noção vaga para categorizar diferentemente o registro das "aptidões naturais" das capacidades que não se sabe situar senão ao lado das invariantes da personalidade. Ou, para dizer de outra forma, qualquer que seja a roupagem conhecida na qual se dissimula a natureza feminina, concretamente, remete-se sempre às mulheres (ou ao feminino do homem enfermeiro) para "humanizar o hospital".

Contudo, as equipes de cuidados não são as únicas no hospital cujo trabalho implica estabelecer uma relação com as pessoas doentes ou em situação de angústia. O componente relacional do trabalho realizado pelo homem nos serviços técnicos hospitalares, assim como sua utilidade social, está até o presente amplamente subestimado ${ }^{2}$. No hospital, excepcionalmente, o trabalho cumprido por homens é menos reconhecido que o exercido por mulheres e é menos valorizado, mesmo quando melhor remunerado (LEMIÈRE; SILVERA, 2008). E, também excepcionalmente, as dimensões ignoradas deste trabalho surgem à luz dos conhecimentos clínicos e teóricos construídos, em princípio, a partir do sofrimento e das formas de inteligência mobilizadas para um trabalho tipicamente feminino.

\section{Quadro teórico e metodológico}

Minha disciplina de referência é a psicodinâmica do trabalho. Psicodinâmica significa que a investigação toma como centro da gravidade os conflitos que surgem do encontro de um sujeito, portador de uma história singular, e uma situação de trabalho cujas características são, em grande parte, fixadas independentemente de sua vontade. Essa definição implica uma teoria do sujeito e uma teoria do trabalho. A primeira refere-se à antropologia freudiana; a segunda, à ergonomia da língua francesa (DEJOURS, 1993).

Nos anos 1970, a ergonomia de língua francesa, sob a direção de Alain Wisner, inverteu o esquema adaptativo da psicologia científica do trabalho. Não se trata mais de adaptar o ser humano ao trabalho, mas o trabalho ao ser humano. A ergonomia de língua francesa revelou a existência de uma diferença irredutível entre o trabalho prescrito, tal como este é concebido pela engenharia de métodos, e a atividade real. Se os trabalhadores não fazem exatamente o que lhes dizem para fazer, não quer dizer que eles sejam indisciplinados, irresponsáveis ou idiotas para compreender a prescrição. Um exemplo simples: é necessário fazer rapidamente, bem e com segurança. Cada prescrição é legítima, mas elas não são conciliáveis entre si. O compromisso realizado será necessariamente instável através do tempo em função da variação das diferentes injunções (pressão na produção, presença do engenheiro de segurança, taxas de defeitos aceitáveis), do estado das máquinas, do número de pessoas presentes ou ausentes, de sua experiência, da fadiga etc. Nenhum trabalhador se realiza em aplicar as prescrições ao pé da letra. Nesta perspectiva, o trabalho é o conjunto de atividades exercidas pelos homens e pelas mulheres para fazer face ao que não é dado pela organização prescrita do trabalho.

O trabalho não pode ser estudado sem referência à autonomia e à inteligência dos que o operam. Sobre esta base ergonômica, o aporte científico da psicodinâmica do trabalho reside em mostrar a importância de considerar também a subjetividade, e não somente a cognição, para adaptar o trabalho ao homem.

O material clínico discutido neste artigo provém de fontes diversas. Nos anos 1990, tive a oportunidade de

\footnotetext{
${ }^{2}$ Trata-se de serviços que asseguram a realização e a coordenação dos trabalhos de construção e de manutenção dos edifícios, a segurança e a manutenção das instalações, a logística, a hotelaria e a cozinha.
} 
coordenar grupos de falas em um Instituto de Formação de Enfermeiros. Isto me proporcionou compreender o ponto de vista dos estudantes enfermeiros sobre o que viviam durante o processo de aprendizagem. Todavia, suas falas não faziam sentido se eu não tivesse investigado paralelamente a vivência das enfermeiras adultas a partir de enquetes em psicodinâmica do trabalho. A metodologia de pesquisa-ação utilizada está explicitada em Dejours (1993), Dessors e Jayet (1990) e Molinier (2006a). Ela é específica ao seu objeto: a análise do sofrimento no trabalho. Ela implica: 1) a existência de uma demanda que emana das pessoas em questão e é centrada sobre a elucidação de seu sofrimento no trabalho; 2) o acordo da direção da empresa e parceiros sociais; 3) a participação em caráter voluntário dos agentes na enquete; 4) coleta de material realizado exclusivamente no seio dos pequenos grupos; 5) um relatório escrito pelos pesquisadores e submetido à validação dos participantes que são os primeiros destinatários.

Utilizo aqui o material de duas enquetes em psicodinâmica do trabalho. A primeira foi realizada junto às enfermeiras trabalhadoras nos serviços cirúrgicos de um hospital de uma cidade da província francesa. A solicitação voltava-se para a "gestão de conflitos" em um contexto de trabalho muito tenso, notadamente porque, diante do fechamento dos pequenos hospitais das cidades periféricas, o hospital tornou-se muito pequeno. A hipótese do trabalho consistia em colocar em evidência a contribuição do trabalho (particularmente em torno da questão dos valores profissionais) nos conflitos que as servidoras consideravam, a princípio, como conflitos pessoais ${ }^{3}$.

A segunda pesquisa é a mais amplamente utilizada neste artigo. Ela refere-se às chefias (supervisores) dos serviços de cuidados e dos serviços técnicos de um centro hospitalar universitário em uma grande cidade. A solicitação foi feita após o suicídio de uma supervisora, que injetou produtos da farmácia do serviço em seu escritório em uma noite de domingo. O diretor do estabelecimento constatou sua morte apenas na segunda-feira pela manhã e, muito transtornado, cometeu a inabilidade de dizer publicamente que aquela mulher era "frágil”. Foi um protesto geral. Seus colegas demonstraram imediatamente que sabiam que ela havia solicitado uma transferência em razão de discordâncias graves com o médico-chefe do serviço. À medida que o pedido fora recusado, eles interpretaram seu gesto de desespero relacionando-o à sua situação profissional e não à sua "fragilidade" pessoal. Não coletamos nenhum depoimento póstumo desta mulher e, portanto, seu gesto não pode ser interpretado no quadro de nosso dispositivo. O que nos importa é que o suicídio foi imputado ao trabalho pelos colegas que se consideravam, eles mesmos, em dificuldade. A demanda transmitida pelo comitê de higiene, segurança e condições de trabalho (CHSCT) ${ }^{4}$ voltava-se para a elucidação do "mal-estar dos gerentes"5.

\section{O ethos enfermeiro: um aprendizado pelo corpo}

As enfermeiras falam freqüentemente de seus anos de aprendizagem como um período particularmente desgastante. Algumas designam mesmo seus anos de estudo como um "buraco negro" que elas preferem esquecer. Não somente as primeiras confrontações com a doença e a morte são árduas, mas as estudantes enfermeiras fazem simultaneamente a experiência das relações sociais de trabalho. Elas devem se conformar ao que lhes é demandado, adotando condutas das quais não compreendem o sentido, ou mesmo que elas desaprovam. As estudantes compreendem que, por questões de assepsia, as jóias sejam proscritas. Mas penteados fantasiosos, mechas de cores azuis ou rosas, maquiagens fortes, o esmalte descascado das unhas dos pés, as pernas mal depiladas são pontos negativos que, contudo, lhes parecem menos justificáveis de se proscrever. Não se pode gritar nos corredores ou gargalhar, nem correr, nem gesticular, nem ser indolente, nem colocar as mãos nos bolsos, nem transpirar... A vida das estudantes é ritmada por comentários indelicados: "Mantenha a postura corretamente"; "Você não é uma dançarina de cabaré"; "Por favor, senhorita, use desodorante". As estudantes deduzem que uma grande parte da avaliação relaciona-se à "nota do aspecto" e que as chefias desejam quebrar as personalidades fortes. Isso não é nada anedótico. As pesquisas realizadas junto às enfermeiras adultas sugerem que as críticas, que têm por alvo o corpo erótico, deixam seqüelas que se aproximam a um traumatismo, ou seja, a uma usurpação psíquica de difícil elaboração. Ao evocar os fatos, mesmo vinte anos mais tarde, o sofrimento e a cólera surgem em seu estado bruto, sempre atuais e não modificados pelo tempo e pela experiência. "Ombros arcados a corrigir", "uma mecha de cabelo saindo da touca" - a crítica surge muitas vezes tão absurda que faltam palavras para designar a amplitude do dano. Em comparação, as enfermeiras são muito menos afetadas pelas observações lúbricas ou machistas de alguns médicos ou pacientes. Elas podem facilmente as circunscrever a partir das categorias do senso comum e, sobretudo, tendo todas juntas a mesma opinião sobre "os homens". Mas os sofrimentos e as humilhações infligidas pelas mulheres adultas às

\footnotetext{
${ }^{3}$ Por um trabalho detalhado desta enquete, ver Molinier (2006 b).

${ }^{4}$ Trata-se de instância paritária, em que são representados a empresa, os sindicatos e os especialistas de saúde e da segurança no trabalho (médico do trabalho, engenheiro de segurança, dentre outros).

${ }^{5}$ Por uma monografia, ver Molinier (2001).
} 
jovens são extremamente personalizados para serem socializados. Tomando como alvo as faltas e as falhas do corpo erótico, elas atingem zonas de fragilidade inconscientes. Um acontecimento de ordem social, inscrito nas relações de dominação entre mulheres, desestabiliza a identidade em um período da vida em que a jovem se encontra e debuta em sua vida sexual.

Na teoria do traumatismo, os eventos exteriores abatem sua eficácia dos fantasmas que eles reativam e abundam de excitação pulsional que desencadeiam. Pela diferença com a psicanálise, a análise clínica do trabalho não permite atingir o inconsciente. Pode-se ao menos interrogar se a impossibilidade de responder às agressões femininas, de outra forma que se submeter a elas, não tem por incidência "congelar" o processo de perlaboraçãa $o^{6}$ da relação real e fantasmagórica com a mãe. Por outro lado, a identificação das enfermeiras, como outro modelo de referência distinto da mãe, parece amplamente comprometida. Insistiremos sobre esse aspecto. As enfermeiras não dizem jamais a uma jovem que ela é "bonitinha" ou "graciosa", mesmo que em sua ausência elas falem desta nesses termos e se consideram tais "qualidades" quando se discute sua avaliação. "A enfermeira modelo" é um negativo, um modelo oco, que aparece somente sob a forma da sanção das expressões livres e de usos singulares do corpo. O sofrimento engendrado pelas intervenções sucessivas das enfermeiras experientes orienta progressivamente a principiante a corrigir sua conduta, até que ela alcance a atitude esperada. Por meio dessa modelagem imperceptível, não-formalizada e, portanto, estreitamente controlada pelo coletivo das enfermeiras, atam-se entre as mulheres as relações de medo, de ódio e de submissão, mas também, algumas vezes, de admiração apaixonada. Aparição, revelação: os termos não são fortes o suficiente para traduzir a devoção emocionada e o entusiasmo com os quais as enfermeiras já adultas se lembram da mulher que encarnou, para elas, o ideal enfermeira. Um ícone. Elas freqüentemente esqueceram o nome, resta apenas uma imagem, aquela de uma blusa vestida com elegância, de um gesto, a uma só vez, preciso e gracioso, de uma voz ponderada e firme.

\section{Da disciplinarização dos corpos ao saber-fazer discreto}

Na psicodinâmica do trabalho, considera-se que toda conduta, mesmo a mais insólita, contém uma racionalidade relacionada às pressões do trabalho. Se as enfermeiras adultas desejassem somente submeter suas alunas, elas se contentariam em lhes pedir obediência e não buscariam lhes modificar em seus corpos. Mas o trabalho de enfermagem é um trabalho sobre e com o corpo. Para tornar-se uma ferramenta eficaz, o corpo das enfermeiras deve, em primeiro lugar, anular-se. O cansaço, a vulnerabilidade, a irritação, o sofrimento devem desaparecer para que a presença da enfermeira seja calmante. Uma apresentação "excêntrica" poderia preocupar os pacientes, torná-los desconfiados ou, ao contrário, os encorajar a liberdades excessivas. O aspecto sereno das enfermeiras é uma das garantias da docilidade dos pacientes. Mas isso não é tudo. Coagindo as estudantes a reprimirem seus movimentos espontâneos, obriga-se a colocar em latência suas necessidades imediatas, a suportar a passividade. A disciplinarização do corpo e a solicitação da passividade são as etapas constitutivas da postura psíquica requerida pelo trabalho de enfermagem. Para fazer bem este trabalho, ou seja, para retirar-lhe o prazer, é preciso poder sentir o sofrimento do outro, o que implica enfrentar a si mesmo e sentir seu próprio sofrimento. A compaixão é a forma de sofrimento gerada pelo trabalho de enfermeira. Por compaixão, é necessário entender aqui literalmente o sofrer-com, a sensibilidade ao sofrimento do outro. A compaixão não é espontânea na experiência das enfermeiras (nem na experiência humana). E este não é o menor dos paradoxos que o trabalho psíquico engendra, na realidade, sob pressão. Entre os estudantes de Enfermagem, o encontro com os pacientes suscita inicialmente as reações de medo, de angústia e de desgosto que apreendem os corpos e geram o pânico e o desejo da fuga. Na atividade das enfermeiras experientes, a compaixão não existe jamais no estado puro. Ela é conflitante com as preocupações ligadas aos imperativos organizacionais: trabalhar em ritmo acelerado, por exemplo, com o excesso de trabalho e a irritabilidade, com o medo e a repulsa que não desaparecem em hipótese alguma, seja pelo desejo ou pela crueldade ${ }^{7}$.

O sofrimento é a espera de uma mão estendida... Mas o sofrimento não se vê, faz-se necessário aprender a adivinhar. De fato, não é o sofrimento que chama a mão estendida, mas a mão estendida que, devido a sua intenção, se esforça para atingir o sofrimento a fim de aliviá-lo. Deste ponto de vista, a eficácia do saber-fazer na Enfermagem depende fundamentalmente de sua discrição. Cada vez em que é necessário aliviar o sofrimento (ou não o aumentar), a fim de não cansar ou de aborrecer a pessoa, e, ao mesmo tempo, para economizar gestos ou deslocamentos inúteis, é

\footnotetext{
${ }^{6} \mathrm{O}$ conceito de perlaboração criado por Freud designa que "os fatos da experiência clínica que mostravam que o conhecimento do esquecido não apaziguava a angústia: 'Ter escutado e ter vivido são duas coisas de natureza psicológica totalmente diferente, mesmo quando têm conteúdo idêntico”" (FREUD, 1915, p. 81). In: CAVALCANTI, M. T. Sobre o “dizer verdadeiro” no espaço analítico. Ágora (Rio J.) [online]. 2004, vol. 7, no. 1 [cited 2008-09-08], pp. 55-72. Available from: <http://www.scielo.br/scielo.php?script=sci_arttext\&pid=S1516-149820040001 00004\&lng =en\&nrm=iso > . ISSN 1516-1498. doi: 10.1590/S1516-14982004000100004. Acesso em 08.set.2008. (N.T.)
}

${ }^{7}$ Para uma análise sobre a psicodinâmica da violência e da ambivalência do trabalho do care, cf. Molinier (2004). 
preciso saber antecipar a solicitação e dissimular os esforços e o trabalho realizado para chegar ao resultado desejado: estar próxima à mão da campainha ou até do copo d'água, mas também propor ao cirurgião o bom instrumento no bom momento etc. Esses saber-fazer são discretos uma vez que os meios aplicados não despertam a atenção do beneficiário e devem ser mobilizados sem esperar, necessariamente, sua gratidão. "Você é meu raio de sol", para retomar uma fórmula bastante citada pelas enfermeiras, é uma das formas de gratificação narcísica endereçada pelos pacientes que atesta e confirma simultaneamente o sentido do trabalho das enfermeiras e sua feminilidade.

A compaixão não tem nada de natural, no sentido essencial do termo. Trata-se de um remanejamento secundário, de uma modificação da subjetividade pelo trabalho. Mas uma vez estabilizada pela experiência, a compaixão torna-se autêntica, ela se passa sem distância, como uma paixão precisamente. O risco é se deixar levar por ela até a consumação e o esgotamento profissional. Voltaremos a este ponto posteriormente.

\section{O tormento dos outros, entre transgres- são e elaboração coletiva}

As situações nas quais as enfermeiras intervêm são pouco visíveis. As modalidades da subjetividade são tão contraditórias e ambíguas que é muito difícil saber o que é preciso fazer e se o fizeram bem. Na enquete realizada no hospital citado, uma bela jovem conta, perturbada, que aceitou, durante várias semanas, ceder ao pedido de um doente que estava na unidade de terapia intensiva, doravante denominada UTI. Ele desejava que ela arrumasse os cabelos de certa maneira que ele achava mais atraente. Preso em sua cama por tubos, os cabelos da enfermeira, pretos, lisos e plenos de vida, eram a única encarnação da qual ele poderia se alegrar. Trata-se ainda de um cuidado ou se trata de uma transgressão, de um jogo erótico? Até onde se pode falar sobre o dom de cuidar sem se perder? A dimensão erótica da relação não é aludida pela enfermeira. Para ela, o gesto de fazer este coque a deixava pouco à vontade. Ela, contudo, realizava o desejo do paciente, não por amor a ele, mas por compaixão. Segundo relatos freqüentes das enfermeiras, o que importa na decisão de transgredir as regras é que os pacientes "não têm mais nada nem outra pessoa", exceto elas. Outros depoimentos complementam este sobre os cabelos e retomam a questão dos limites a não serem ultrapassados, mesmo por compaixão. Um ancião impotente queria dormir com uma camisola de renda rosa. As enfermeiras aceitaram colocá-la, mas recusaram ir mais adiante à perversão e a administrar lavagem intestinal que ele também implorava.

As enfermeiras não podem descrever seu trabalho através de generalizações ou modelá-lo sob a forma de estatísticas ou diagramas. Para compreender o que fazem, as enfermeiras são levadas a contar uma sucessão de histórias por meio das quais se amplia a densidade do drama humano que elas têm por missão suportar. Embora o trabalho de enfermagem seja inapreensível pelas ferramentas de gestão, ele é, portanto, perfeitamente acessível sob a forma de uma narração. Já que as enfermeiras se dirigem a outros seres humanos, gestores e médicos, considerados como inteligentes, por que elas não se fazem compreender? Esperamos ter apresentado um primeiro panorama. É necessária certa coragem para aceitar a reconstituição pública desses depoimentos sem os expurgar, sem os censurar diante da vida. Querer tanto que suas alunas sejam respeitáveis se deve também à suspeita sobre a moralidade da mulher que toca o corpo dos outros e suporta a visão do sangue. Ora, graças a essas histórias, a experiência do trabalho com compaixão se transmite e se sedimenta. O que é necessário fazer quando encontramos duas senhoras idosas todas as manhãs na mesma cama? Deve-se tolerar que um paciente beba às escondidas? O cotidiano nesta profissão é feito desses imprevistos. Cada situação inusitada é fortemente estampada pela personalidade dos pacientes e das enfermeiras, mas, graças à sucessão de histórias, todas as situações se inscrevem em uma mesma cadeia de sentido. Não é a dimensão íntima do prazer por si só que orienta a deliberação das enfermeiras, mas o objetivo compartilhado, o mais importante do trabalho de cuidados: fazer algo dirigido ao outro de forma que ele sofra o menos possível. Não é a transgressão em si que é julgada, mas seu grau de pertencimento à esfera do care $^{8}$ e do zelo. Inversamente, é também graças à deliberação que as enfermeiras se protegem de deslizar de forma incontrolada na ladeira da transgressão e de suas ambigüidades. A sabedoria prática toma tempo, em particular aquele da pausa para o café, um tempo improdutivo e, portanto, indispensável segundo a ótica da saúde das enfermeiras e da humanidade dos cuidados.

\footnotetext{
8 “Em francês o termo 'care' é freqüentemente relacionado aos termos de solicitude, de cuidados, de atenção e ou de responsabilidade. Estes termos abarcam uma ampla proporção do campo semântico, mas nenhum deles isoladamente tem condições de considerar a complexidade deste gênero de relação. Ao mesmo tempo, resposta prática às necessidades concretas que são sempre singulares de outrem (quer sejam próximas ou não), atividades necessárias para preservar pessoas 'dependentes' ou 'autônomos', trabalho realizado competentemente tanto na esfera privada quanto na pública, engajamento moral segundo o qual não se trata ninguém como parte insignificante, o 'care' é necessariamente uma ação concreta ligada às particularidades das situações e das pessoas" (PAPERMAN; LAUGIER, 2005). O conceito de "care" está, em grande parte, na origem do desenvolvimento de perspectivas feministas na ética. A escolha de conservar o termo em inglês foi feita, portanto, para tornar explícita a vontade de se inscrever no campo da epistemologia feminista contemporânea.
} 


\section{Auto-desprezo e domesticação das pulsões}

Voltemos às relações hierárquicas entre mulheres, sem dúvida a dimensão mais desconhecida da experiência em enfermagem, mas não a menos dolorosa. Se nos detivermos à clínica das estudantes enfermeiras, parece que a raiva e as rivalidades entre enfermeiras não podem ser superadas porque elas atingem, em cada uma, as zonas mais favoráveis da psique. Se for esse o caso, trabalhar se tornaria insuportável. Mas a análise das situações do trabalho sugere que, entre enfermeiras experientes, os sofrimentos gerados pelas relações hierárquicas podem, em parte, ser elaborados coletivamente, sob a condição da chefia aceitar se curvar ao jogo cujas regras terão sido definidas pelas enfermeiras.

Ao longo da pesquisa realizada com as chefias, uma mulher que trabalhava na UTI à noite se declarava como um modelo de chefia "maldosa", uma linha psico-rígida, extremamente exigente com sua equipe e sempre contrária ao mínimo sinal de comportamentos livres, particularmente relativos ao corpo e ao modo de se vestir. Esta mulher assume, então, sem embaraço, a posição agressiva denunciada pelas enfermeiras estudantes. O paradoxo é: em nome da ética e vinculada à qualidade dos cuidados, ela reconhece infligir o sofrimento ao seu pessoal. Trata-se de uma contradição moral. Como ela se vira? Ao final do último encontro para restituição do relatório da enquete, no momento que o grupo iria se separar, ela afirma que o trabalho na UTI exerce uma forte pressão sobre o quadro de pessoal e que uma boa chefe deve, muitas vezes, saber deixar livre o pessoal. Ela conta, então, a seguinte história: sabendo que ela participava de um curso de dança, as enfermeiras de sua equipe vieram uma bela noite com vestes de balé alugadas, apostando que todas, assim vestidas, iniciariam a dançar. Projeto curioso caso se considere o caráter rígido e a silueta daquela senhora. Jogando com o efeito de contraste entre sua pessoa e a rapidez de uma bailarina, a narradora consegue nos fazer irresistível à evocação de todo o grupo, evoluindo ao passar da meia-noite, nos corredores da ala de trabalho. Mas a história não para por aqui. No dia seguinte, um paciente relatou ao médico sua surpresa de ter visto mulheres dançando com saias de balé nos corredores do hospital... O que lhe rendeu um tratamento suave à base de neurolépticos! A equipe da noite jamais admitirá a origem deste "delírio". Entre as chefes que ouviram a história, algumas choraram de rir. Entre o riso e as lágrimas: o clima emocional é típico do coletivo enfermeiro. $\mathrm{O}$ que significa que nos depoimentos das enfermeiras não há apenas uma dimensão moral-prática, mas há também uma função de catarse.
A manutenção do corpo erótico está, novamente, no centro das condutas insólitas. Trata-se, para as subordinadas, de subverter as relações de dominação, não para abolir as hierarquias, mas para testar o grau de pertencimento da chefe ao coletivo enfermeiro. Está com elas, é enfermeira como elas, ou está contra elas? A chefe das enfermeiras deve de certo modo provar que ela compreende as demais, seu sofrimento e as modalidades coletivas de sua catarse. Ela faz parte do mesmo mundo vivido; sabe que o domínio de si e das expressões singularizadas do corpo têm seus limites; reconhece que a excitação pulsional reprimida deve, muitas vezes, encontrar no trabalho resultados aceitáveis graças aos quais ela consegue ser socializada, e mesmo valorizada, em benefício de todas. Ela aceita que uma atividade excepcional, entre iguais, tenha um valor reconciliador que anula os ressentimentos e os rancores. O teste é decisivo no que concerne à legitimidade e à autoridade da chefe. Toda a arte consiste em assumir o ridículo sem, contudo, deixar de ser a chefe. Foi bem feito fazê-lo? Esta é a questão moralprática que ela corre o risco de colocar em discussão com suas colegas ao final da pesquisa. Isto pode ser bom no saber-fazer das violações. É em nome da compaixão, desta vez frente-a-frente ao sofrimento das equipes, que a dupla transgressão da chefe (ela dança nos corredores, ela não revela a origem do "delírio") lhe parece finalmente justificada.

O depoimento coloca também a intriga entre as relações de subordinação do corpo enfermeiro - tomado desta vez em seu conjunto - e em relação aos médicos, em particular ao que prescreveu o neuroléptico ${ }^{9}$. As chefias se divertem com a negação da realidade do médico, mas é significativo que a autenticidade de sua própria relação com o sofrimento e com as defesas da equipe se exprima apenas no interior do coletivo. $\mathrm{O}$ humor diminui consideravelmente o peso das relações com os médicos, mas, diferentemente do que minimiza entre as enfermeiras, não modifica as condições externas. A evocação das saias de balé surge durante os últimos minutos da enquete, em um momento em que todos sabem que tais observações não estarão registradas no relatório escrito. Contudo, somente as chefes aceitam apresentar aos pesquisadores a complexidade da vida das equipes e seu próprio posicionamento ambíguo em relação aos médicos e aos administradores, de um lado, e às equipes de enfermeiras, de outro, em relação à preocupação com eficácia de uma parte e à preocupação com as equipes de outra parte.

\section{A coordenação enfermeiras: uma co- munidade de sensibilidade}

Na França, no final dos anos 1980, os sindicatos dos trabalhadores em hospitais foram colocados à

${ }^{9}$ A história não revela se as enfermeiras da noite realmente administraram o neuroléptico! 
margem por um movimento social original: a coordenação enfermeira. Este período marcou uma virada na história da profissão e contribuiu para legitimar aos enfermeiros os valores aos quais estão associados. Mas seu poder de agir em conjunto não atingiu seu objetivo: modificar o ponto de vista dos representantes do Estado. As escolhas políticas em matéria de reestruturação do sistema de cuidados continuaram a ser feitas sem considerar as dimensões específicas da atividade dos enfermeiros. As enfermeiras não dispunham de uma teoria do trabalho que lhes permitisse ir até o final de seu projeto: o reconhecimento de seu profissionalismo sobre a vertente do trabalho do care. Faltava-lhes inventar nova retórica que não arruinasse sua experiência no registro do anedótico.

Os representantes do Estado, após um primeiro momento de desestabilização, conseguiram, finalmente, reduzir a legitimidade e o caráter político do movimento, reduzindo-o ao pathos feminino. Um membro do gabinete do ministro da saúde resume a amplitude do mal-entendido desta forma:

É inacreditável: essas moças da coordenação nos contam, cada uma delas, com detalhes, seus problemas da vida cotidiana! Elas estão emocionadas, nos tocam, mas como negociar com uma categoria de vida?

Observemos a proposição de uma das interessadas:

Nós percebemos que a qualidade da atenção e dos cuidados não é problema deles. Para eles, é necessário que os cuidados funcionem sem considerar a dimensão do humano. Eles não sabem, portanto, o que é um hospital, nossa vida. ${ }^{10}$

O desafio do conflito entre as enfermeiras e o Estado se situa no nível da definição da vida. Para as enfermeiras, a vida, a sua assim como a das pessoas enfermas, não pode ser reduzida a um substrato biológico no qual é suficiente aportar uma resposta instrumental. A vida se define como a experiência de ser vivo, que sofre e que age.

Concluiremos esta parte do texto a partir de exemplo de situação em que $a$ vida foi esquecida. Outra chefe, na enquete já mencionada, sempre qualificando sua tarefa como "a de um titã", afirma: "Não podemos partir (do trabalho) porque as pessoas que cuidamos vivenciam situações humanamente extremas e nós somos as extremidades do extremo". Em que registro interpretar sua exaltação? Trata-se de um problema associado ao que ela é, de sua estrutura de personalidade ou há algo relacionado ao que ela faz? Em seu serviço de pediatria, o chamado plano anti-bronquiiolite é aplicado sem que um espaço suplementar, para acolher as crianças, tenha sido realmente previsto. Em plena epidemia, colocam-se os bebês até nos almoxarifados. Além disso, as enfermeiras veiculam a epidemia e contaminam seus próprios filhos. Mas este risco não foi previsto, nem, como conseqüência, os meios para substituir aquelas que devem se ausentar para cuidar dos seus filhos. A chefe ficará "no campo", para acalmar as famílias, substituir as enfermeiras, fazer a manutenção, aquecer as mamadeiras, esvaziar as vasilhas de leite... durante todo o tempo que suas forças lhe permitirem.

Esta chefe que sofre de insônia e de esgotamento profissional, como a maior parte de suas colegas, tenta regularmente transmitir o que se passa - a realidade do cotidiano - para a direção. Sem sucesso. O problema não é compreendido como sendo da organização do trabalho, mas, precisamente, da "devoção" das chefias. Assim, sua palavra é freqüentemente desqualificada, registrando-a como um caso de fragilidade pessoal:

Você exagera... pare de dramatizar, você é muito conscienciosa, você é muito exigente, pense menos nos doentes, descanse, faça, então, outra coisa além de trabalhar, você tem certeza que está bem? Você está com problemas?

\section{Os serviços técnicos: a face oculta da instituição}

A clínica que passamos a expor é estrato da enquete em psicodinâmica do trabalho conduzida junto à hierarquia imediata dos serviços de alimentação coletiva, de hotelaria, de manutenção, de logística e de segurança contra incêndio em um centro hospitalar universitário. Todos são "homens de campo" e técnicos altamente qualificados na área à qual estão vinculados. Seu métier é, para cada um deles, orgulho e uma referência identitária forte: eles são cozinheiros, eletricistas etc.

Os serviços técnicos hospitalares enfrentaram modificações tecnológicas e um crescimento de exigências em termos de conforto e qualidade de vida. Inúmeras atividades no campo dos transportes, da manutenção e da limpeza são atualmente terceirizados. Algumas profissões julgadas não-rentáveis desapareceram (especialmente as de pintura, marcenaria, encanador, pedreiro, ferreiro, eletricista, serralheiro). Outras necessidades surgiram nas áreas de informática, biomedicina, hotelaria e na unidade de terapia intensiva. Globalmente, o nível de competência requerido foi elevado em um contexto de contratação reduzido em que os titulares são chamados a "evoluir". A maior parte das atividades de manutenção implica conhecimentos em eletrônica, desde a reparação das fechaduras, das camas hospitalares, das persianas, da tubulação e do esgoto, de aquecedores ou do ar-condicionado. Trabalhar na cozinha hospitalar exige se alinhar aos procedimentos de higiene e segurança rígidos etc. Além disso, os responsáveis pelos serviços técnicos se deparam com problemas de reclassificação dos trabalhadores; algo bastante complicado, pois

${ }^{10}$ As citações foram extraídas de Kergoat; Imbert; Le Doare; Senotier, 1992, p. 107 e 98. 
estes serviços cumprem, já há muito tempo, a delicada missão de utilizar servidores "inaptos" para as atividades de cuidados devido a diversas razões (alcoolismo, toxicomania, problemas de comportamento, lombalgias etc.).

Antes, nas cozinhas, a ausência de tecnologia sofisticada permitia empregar auxiliares de cozinha ou descascadores de batatas. Os jardins mostravam-se muito úteis para realocar trabalhadores para varrer folhas mortas e, da mesma forma, os serviços de lavanderia, de transporte etc. Ora, não constava nos hábitos do hospital público valorizar a missão social que foi substituída discretamente pelos serviços técnicos e, às vezes, em detrimento da qualidade da prestação do serviço (especialmente na cozinha). Desta invisibilidade, os serviços técnicos pagam hoje um preço importante, o da vergonha e o da desvalorização. "Indesejáveis", "dejetos", "guetos", "braços quebrados", "serviços de lixo”...: esses termos utilizados pelos responsáveis técnicos testemunham o que estes tendem, espontaneamente, a atribuir à presença dos trabalhadores em dificuldade ao balanço negativo de seus serviços. Como estão, agora, submetidos a resultados, a inserção dos "braços quebrados" (expressão recorrente na enquete) se tornará impossível. Enquanto a intolerância em relação aos trabalhadores em dificuldade cresce entre o pessoal operacional, os responsáveis são, algumas vezes, obrigados a realizar, eles mesmos, o trabalho reservado às empresas subcontratadas cujas equipes não apresentam, na maioria das vezes, desempenho suficiente diante dos novos critérios de gestão ${ }^{11}$.

\section{No hospital, todo o trabalho encerra uma dimensão do care}

A dimensão da compaixão está no centro das críticas tecidas pelas chefias em relação à terceirização. Por exemplo, quando uma televisão ou telefone quebravam à noite, o reparo antes era assegurado nas horas seguintes pelos técnicos. Hoje, a empresa contratada realizará o reparo somente no dia seguinte, nos horários definidos no contrato com o "cliente", o hospital. Solução inaceitável para as chefias, pois se trata de pessoa doente e privada, durante toda a noite, da distração ou do contato com seus familiares. Por outro lado, os servidores, que desejavam consertar a instalação para atender a um paciente, são impedidos pelas trancas e proteções colocadas pelas prestadoras de serviços nas instalações para lutar contra a concorrência.

Instalar um chuveiro, pintar um aquecedor, reparar uma cortina, trocar uma lâmpada, vários consertos ou trabalhos menores ocorrem próximos à cama do doente. A preocupação em não incomodar, cansar, deixar uma pessoa na corrente de ar, não expor aos odores dos solventes, dentre outras, está tão presente quanto a preocupação de realizar bem o ato técnico. Admite-se, então, que o ato técnico efetivo é aquele que atinge a melhor conciliação entre a eficácia técnica, de uma parte, e a segurança física das pessoas e o bem-estar dos pacientes, de outra. Neste ponto de vista, os trabalhadores de serviços técnicos pertencem ao mesmo mundo vivido pelos servidores do pessoal dos serviços de atenção e cuidados. A competência dos serviços técnicos não é unicamente técnica, ela contém, ao mesmo tempo, compaixão. Mas, diferentemente das enfermeiras, este sentimento não se configura como uma característica da "natureza" ou da "vocação" dos homens exercendo um trabalho técnico. O trabalho técnico hospitalar seria um trabalho técnico como os outros, o que justifica ter sido possível dividir as tarefas entre prestadores externos e serviços técnicos internos, de acordo com critérios estritamente econômicos. A manutenção dos elevadores é um exemplo.

Quando um elevador quebra, a empresa contratada é responsável pelos reparos técnicos, enquanto os serviços internos têm a responsabilidade de retirar as pessoas do seu interior (podendo ser processados criminalmente em caso de morte). Neste trabalho de retirada, tratar-se-ia, em teoria, apenas de acalmar as pessoas, de fazê-las sair pelo alçapão, ou se elas não querem ou não podem sair, de descer e ficar junto delas no elevador. Este papel de proteção não é simples de assumir. Mas a situação pode tornar-se mais delicada. A prestadora deve intervir em um prazo máximo estabelecido por cláusula contratual (duas horas). Na realidade, o mecânico chega, assim que possível, mas as chefias de manutenção não têm jamais certeza que ele respeitará o prazo. Além do mais, acreditam que a prestadora não está muito preocupada devido à pequena penalidade que lhe será imputada em caso de ultrapassar o prazo definido em contrato. Neste tempo, nos elevadores do hospital, transitam pacientes deitados, com soro aplicado, inválidos..., os quais não se pode correr o risco de deixar a espera. O caso de uma jovem à beira da morte no elevador em pane, cujos pais encontram-se à porta, representa os dramas que revelam como os serviços técnicos não podem ficar inativos. A retirada pode, portanto, ser iniciada antes da chegada do mecânico e, mesmo que os trabalhadores do hospital não tenham o direito de mexer na mecânica do elevador ou de repará-lo, pode ser que o façam, de qualquer forma. Podem correr, assim, o risco de sofrer sanções pela infração cometida, para bem fazer, ou seja, para agir da melhor forma em defesa dos interesses dos enfermos que estão no elevador.

Os serviços técnicos não têm, portanto, apenas função instrumental. Nos objetivos vinculados à tarefa, figuram igualmente os objetivos relativos às pessoas: aos doentes e à manutenção de suas condições de vida, de transporte, de segurança, mas também em relação ao pessoal e aos serviços técnicos, como os de

${ }^{11}$ É importante observar que não conduzimos investigações junto aos trabalhadores destes serviços. 
recepção, integração e reintegração de servidores em dificuldade. A questão não é, então, saber se - para evocar um slogan mencionado na enquete - "a alimentação coletiva faz parte dos cuidados” ${ }^{12}$. Não se trata de inscrever a dimensão da compaixão do trabalho técnico hospitalar em uma visão prescritiva, como qualquer coisa a ser feita, mas de reconhecer que ela simplesmente está presente, já mobilizada pelo trabalho técnico hospitalar.

\section{Fora da técnica, não há trabalho?}

Para inventar as formas graças às quais a missão social dos serviços técnicos e o lado do seu trabalho realizado com compaixão poderiam ser colocados em discussão no interior da instituição, seria necessário preliminarmente que as chefias colocassem em questão a definição masculina do trabalho: fora do trabalho técnico, não há trabalho! Este ponto de vista masculino é particularmente perceptível nas diversas reuniões das quais as chefias devem participar. Para nossa grande surpresa, as chefias contabilizam apenas como tempo de trabalho quando estão realmente ativos, isto é, os poucos minutos que cuidam dos processos. O restante do tempo de reunião, improdutivo e que pode ser longo, não é considerado como trabalho, mas como perda de seu tempo, levando-os ao tédio. Por isso, as chefias não têm sentimento de trabalhar muito, mesmo que ultrapassem o número de horas previstas em lei! Eles ficam surpresos com o fato de termos não somente outra concepção em relação ao tempo, mas de pensarmos também que o tédio pode ser uma obrigação psicológica, um sofrimento gerado pelo trabalho!

Encontra-se a mesma definição do trabalho, reduzido à sua objetivação técnica, nas críticas endereçadas aos servidores que dizem consagrar tempo a informar as pessoas perdidas no hospital. Um álibi, segundo algumas chefias, para camuflar o que é, na realidade, apenas indolência e preguiça. Ora, a despeito da boa sinalização, os pedidos de informação são freqüentes e parte integrante do trabalho dos servidores que devem mesmo, algumas vezes, acompanhar pessoas idosas ou deficientes. Trabalho inverificável, incontrolável, não mensurável e, portanto, muito útil. "Ele trabalhou duas horas, o resto do tempo ele ficou dando informação..." diz um dos chefes. O exagero da colocação é altamente significativo de sua inquietude. Em um contexto determinado pelo medo de ver as dificuldades nos serviços técnicos crescer pela falta de bons resultados, as chefias temem que seus subordinados possam passar a imagem de pessoas desocupadas e, então, inúteis. Mas, ao mesmo tempo, as chefias técni- cas correm o risco de esquecer as pessoas enfermas e as dificuldades dos trabalhadores ao investir nas novas formas de avaliação da gestão do trabalho. Toda a dimensão relacional do trabalho, devido ao contato com as pessoas hospitalizadas (e o tempo que ele toma), pode ser escamoteada.

As chefias técnicas, como os sindicatos, mostraram-se impotentes face ao desmantelamento dos serviços técnicos hospitalares. As chefias interpretam seu fracasso relativo à reestruturação como uma fatalidade, uma conseqüência das divisões profissionais. A experiência e a "mentalidade" dos eletricistas não seriam comparáveis com as dos cozinheiros ou dos pedreiros. Nossa enquete sugere que é se re-apropriando da dimensão mais invisível de sua atividade, a relação com as pessoas enfermas ou com os trabalhadores em dificuldade, que as chefias dos serviços técnicos e, talvez, seus subordinados poderiam superar seus atos corporativistas para construir uma comunidade de pertencimento e regras compartilhadas para a ação. Isso implica um trabalho de mudança de foco, o que não é evidente para homens, orgulhosos, antes de tudo, de suas competências técnicas.

Por hora, incapazes de descrever o trabalho efetivo, as chefias técnicas são ainda desprovidas para identificar o que, talvez, deveria ter sido feito e não é feito. O risco é que a realidade retorne brutalmente sob a forma de acidente. Ora, o medo crescente de não dominar a periculosidade das situações é pouco compatível com a expressão da vivência subjetiva do trabalho. Sabese, com efeito, por outros estudos realizados junto a coletivos masculinos (especialmente na construção civil, na cirurgia, na polícia, na indústria de processos contínuos), que os homens lutam contra o sofrimento no trabalho, colocando em prática estratégias coletivas de defesas que constituem um sistema de condutas e de representações sociais centradas sobre valores vinculados à virilidade (força, coragem, desprezo pelo perigo). Essas estratégias coletivas de defesa visam modificar, transformar e eufemizar, para não dizer anestesiar, a percepção que os homens têm da realidade e os faz sofrer. Para dizer em outros termos, a cooperação defensiva entre os homens visa opor uma comunidade da negação ao real do sofrimento e da vulnerabilidade humana (DEJOURS, 1993) ${ }^{13}$.

Um homem, um verdadeiro homem, não exprime seu medo, nem seu estado de alma, sobretudo diante de outros homens. Os homens têm um "pudor", nos dizem os chefes técnicos, quando falam das dimensões da experiência sensível. Após a conclusão da pesquisa, reconheceram, com emoção, que pela primeira vez foram capazes de falar conjuntamente sobre a dimen-

\footnotetext{
${ }^{12}$ Originalmente no francês, o slogan apresenta uma rima - “la restauration est un soin” - de adaptação limitada à língua portuguesa. (N.T.)

${ }^{13}$ As enfermeiras não opõem uma negação da realidade ao sofrimento. Isso não significa que estejam "sem defesas”. Elas colocam em prática uma estratégia de elaboração do sofrimento na qual a narração e o debate ocupam um lugar central. Uma vez que apresentam as provas aos colegas, as mulheres, diferentemente dos homens, podem expressar seu sofrimento e mesmo aparecer ridículas sem colocar em risco sua identidade sexual. Sob a condição, todavia, que em suas condutas e em seus depoimentos o sofrimento possa encontrar saídas criativas, socialmente valorizadas, ao menos entre pares, e se transformar em prazer. Temos uma amostra disso no caso da estratégia das vestes de balé.
} 
são humana do seu trabalho e do sofrimento que ele gera. Nossa enquete permitiu abrir uma "brecha" nas defesas das chefias técnicas. Ela indica apenas pistas que merecem análises mais aprofundadas. Assim, não sabemos como os homens que trabalham nos serviços técnicos hospitalares elaboram a dimensão da compaixão em seu trabalho e mesmo se o fazem de outra forma que não no isolamento de um colóquio singular ${ }^{14}$. Com efeito, pela diferença com as enfermeiras, o trabalho com compaixão do pessoal técnico não parece se constituir nem em objeto de uma construção coletiva, nem em regras profissionais, nem em uma tradição estabilizada em uma arte de viver.

\section{Conclusão}

Colocar em visibilidade o lado da compaixão no trabalho técnico poderia permitir derrubar, ao menos parcialmente, a clivagem entre os técnicos e as enfermeiras (incluídas as auxiliares). Até o presente, as ações tomadas por um ou por outros podiam ser apenas separadas. Coordenação das enfermeiras, de um lado, ação sindical, do outro: sem o reconhecimento mútuo do sofrimento, do trabalho e dos valores, qualquer mobilização coletiva na ação era simplesmente impossível (DEJOURS, 1998). Concretamente, estamos, de fato, longe do desejável. Em primeiro lugar, porque o pessoal dos hospitais, capturados pelo drama humano que eles têm por missão sustentar, estão exaustos. Em segundo lugar, porque são eles, e não os gestores, que suportam o peso esmagador e deletério da culpa de mal fazer, de "desumanizar o hospital". Enfim, e este não é o menor dos problemas, porque mesmo que o trabalho dos agentes técnicos seja menos valorizado que o das enfermeiras e mesmo que sejam menos qualificados, as tabelas salariais são nitidamen-

\section{Referências}

DEJOURS, C. Travail: usure mentale. De la psychopathologie du travail à la psychodynamique du travail. Paris: Bayard Editions, 1993.

Mai 68, travail et subjectivité: rendez-vous manqué ou détour nécessaire? Travailler, Paris, n. 1, p. 123-136, 1998.

DESSORS, D.; JAYET, C. Méthodologie et action en psychopathologie du travail. À propos de la souffrance te desfavoráveis e discriminatórias para as enfermeiras e para as auxiliares de enfermagem. Quaisquer comparação e aproximação entre os dois tipos de profissão implicariam em revisar as fórmulas de cálculo e os critérios de remuneração (LEMIÈRE; SILVERA, 2008).

De qualquer modo, as enfermeiras e os técnicos de manutenção dividem, devido a sua atividade, a mesma preocupação. A desnaturalização do saber-fazer ocultado pela feminilidade socialmente construída mostra que o trabalho de care não repousa na boa vontade ou sobre a grandeza da alma. Como a "devoção" está na origem do esgotamento, cuidar pressupõe condições organizacionais concretas. Inicialmente, espaços de deliberação entre pares, para lembrar, para elaborar o sofrimento gerado pelo trabalho, para arbitrar sobre o que é conveniente ser feito; em seguida, possibilidades para fazer compreender as dificuldades do trabalho em um espaço público interno à instituição.

$\mathrm{Na}$ desconstrução do sistema social dos sexos, o desafio não se resume apenas ao desenvolvimento, pelas mulheres, de potencialidades humanas, mesmo aquelas indevidamente decretadas como masculinas. O desafio é também - e pode ser antes de tudo — que a sensibilidade ao sofrimento não seja mais desvalorizada por ser considerada como naturalmente feminina. A experiência sensível e suas formas de expressão públicas devem ser liberadas da prisão do gênero antes que nossas sociedades ocidentais se arruínem em uma deriva abstrata e cínica, deixando apenas à vida, como saída, o isolamento e o desespero. O trabalho de atenção e cuidados, para retomar as palavras de Jean Oury (2008), é um “trabalho inestimável”, no sentido que ele não é mensurável (particularmente pelos métodos de gestão), cujo valor não tem preço, não é “avaliável”. Diante disso, coloca-se a questão paradoxal de saber como remunerar ao justo valor o que é inestimável do ponto de vista da civilidade.

des équipes en réinsertion médico-sociales. Revue Prévenir, Marseille, n. 20, p. 31-42, 1990.

KERGOAT, D.; IMBERT, F. E.; LE DOARE, H; SENOTIER, D. Les infirmières et leur coordination (1988-1989). Paris: Éditions Lamarre, 1992.

LEMIÈRE, S.; SILVERA, R. Les multiples facettes des inégalités de salaire entre les hommes et les femmes. In: CORNET, A.; LAUFER, J. Genre et ressources humaines. Paris: Vuibert, 2008.

\footnotetext{
${ }^{14}$ Algumas chefias técnicas, entre os mais velhos e, particularmente, entre os responsáveis pela segurança contra incêndios, parecem ter desenvolvido modalidades sensíveis similares às das enfermeiras. Sabendo que eles organizam, entre outras, formações para as enfermeiras, uma hipótese que pode ser levantada é que uma parte da elaboração da dimensão da compaixão se opera, para eles, durante os encontros, formais ou informais, com as equipes de cuidados. Deve ser notado que estes senhores testemunharam em diversas ocasiões sobre seu isolamento no meio técnico.
} 
PAPERMAN, P.; LAUGIER, S. Le souci des autres. Éthique et politique du care. Paris: Éditions de l’EHESS, 2005.

MOLINIER, P. Souffrance et théorie de l'action. Travailler, Paris, n. 7, p. 131-146, 2001.

O ódio e o amor, uma caixa preta do feminismo? Crítica da ética do devotamento.

Psicologia em Revista, Belo Horizonte, v. 10, n. 16, p. 227-242, 2004.
Les enjeux psychiques du travail.

Introduction à la psychodynamique du travail. Paris: Payot, 2006a.

Le masochisme des femmes dans le travail: mythe sexiste ou défense professionnelle? Le cas des infirmières de bloc opératoire. Psychologie Clinique et Projective, Paris, v. 12, p. 211-230, 2006b.

OURY, J. Le travail est-il thérapeutique? Travailler. Paris, n. 19, p. 15-34, 2008. 